\title{
Los movimientos de Economía Social en zonas de conflicto armado en México
}

Social Economy movements in zones of armed conflict in Mexico

\author{
Movimentos da Economia Social em zonas de conflito armado no \\ México
}

\section{Nadia Eslinda Castillo Romero ${ }^{1}$}

Recibido: 11 de noviembre de 2019 Aprobado: 20 de diciembre de 2019

Publicado: 15 de febrero de 2020

Cómo citar este artículo: Nadia Eslinda Castillo Romero. Los movimientos de Economía Social en zonas de conflicto armado en México. DIXI 31. Enero de 2020, 1-23. DOI: https://doi.org/10.16925/2357-5891.2020.01.04

Artículo de investigación. https://doi.org/10.16925/2357-5891.2020.01.04

1 Doctora en Sociología. Coordinadora de la Maestría en Gestión de Empresas de Economía Social de la Universidad Iberoamericana Puebla. Profesora e investigadora, Universidad Iberoamericana Puebla. Desde el 2005 consultora de proyectos de Economía Social en Desarrollo y Aprendizaje Solidario.

Correo electrónico: eslinda.castillo@iberopuebla.mx 


\title{
Resumen
}

Objeto: el presente artículo deriva de la reflexión inicial plasmada en el libro Economía Social en contextos de violencia: México y Colombia. Este proyecto tuvo por objetivo la formación de orientadores de economía social que contribuyeran a la generación y el acompañamiento de empresas de Economía Social en zonas históricamente empobrecidas y ahora violentadas por el narcotráfico para que, por medio del trabajo comunitario, emprendieran herramientas solidarias que coadyuvaran a la pacificación social.

Metodología: se observaron los primeros resultados del proyecto "Fortalecimiento de proyectos económicos en territorios de alta vulnerabilidad y situación de violencia", que llevó a cabo el Laboratorio de Innovación Económica y Social (LAINES) de la Universidad Iberoamericana Puebla, México en el 2017. Se aborda el caso de Tancítaro y Cherán en el estado mexicano de Michoacán.

Hallazgos: observamos que la autonomía económica a través de la generación de experiencias y circuitos de economía social es un proceso de largo aliento.

Palabras clave: Cherán, construcción de paz, economía social, Tancítaro, violencia.

\begin{abstract}
Objectives: This article derives from the initial reflection embodied in the book Economía Social en contextos de violencia: México y Colombia. The objective of this project was to train social economy counselors who would contribute to the generation and accompaniment of Social Economy companies in historically impoverished areas now rife with drug trafficking so that, through community work, they could undertake solidarity tools that would contribute to social pacification.
\end{abstract}

Methodology: The first results of the project "Strengthening economic projects in territories of high vulnerability and situations of violence" were observed, which was carried out by the Economic and Social Innovation Laboratory (laines) of the Universidad Iberoamericana Puebla, México in 2017. The case of Tancítaro and Cherán in the Mexican state of Michoacán is addressed.

Findings: We observe that economic autonomy through the generation of experiences and social economy circuits is a long-term process.

Keywords: Cherán, peace building, social economy, Tancítaro, violence.

\section{Resumo}

Objetivos: Este artigo parte da reflexão inicial consubstanciada no livro Economía Social en contextos de violencia: México y Colômbia. O objetivo deste projeto era formar conselheiros de Economia Social que contribuíssem para a geração e acompanhamento de empresas de Economia Social em áreas historicamente empobrecidas hoje e cheias de tráfico de drogas para que, por meio do trabalho comunitário, pudessem realizar ferramentas solidárias que contribuíssem para a pacificação social. .

Metodologia: Foram observados os primeiros resultados do projeto "Fortalecimento de projetos econômicos em territórios de alta vulnerabilidade e situações de violência", realizado pelo Laboratório de Inovação Econômica e Social (LAINES) da Universidad Iberoamericana Puebla, México em 2017. O é abordado o caso de Tancítaro e Cherán no estado mexicano de Michoacán.

Resultados: Observamos que a autonomia econômica por meio da geração de experiências e circuitos de economia social é um processo de longo prazo.

Palavras-chave: Cherán, construção da paz, economia social, Tancítaro, violência. 


\section{INTRODUCCIÓN}

El presente artículo deriva de la reflexión inicial plasmada en el libro Economía Social en contextos de violencia: México y Colombia, coeditado por la Universidad Iberoamericana Puebla y la Universidad Cooperativa de Colombia. Asimismo, este artículo resume los resultados de la primera etapa de la investigación "Los movimientos de Economía Social en zonas de conflicto armado en México", adscrita a la Dirección de Investigación y Posgrado de la Universidad Iberoamericana Puebla. La investigación citada tuvo como objetivo analizar cómo los ejercicios de economía social contribuyen a la construcción de un tejido social armónico y solidario con una economía en pro del bien común, en zonas de conflicto armado derivado del narcotráfico en los municipios de Cherán y Tancítaro en Michoacán, México.

En este sentido, el propósito de la presente investigación fue identificar los primeros resultados del proyecto "Fortalecimiento de proyectos económicos en territorios de alta vulnerabilidad y situación de violencia", que desarrolló el Laboratorio de Innovación Económica y Social (LAINES) de la Universidad Iberoamericana Puebla, México, en el 2016 y el 2017. Este proyecto tuvo por objetivo la formación de orientadores de economía social que acompañaran la generación y puesta en marcha de empresas en zonas históricamente empobrecidas y ahora violentadas por el narcotráfico, a fin de que emprendieran herramientas solidarias que contribuyeran a la pacificación social por medio del trabajo comunitario. Entonces, el artículo recoge los primeros resultados obtenidos en la primera etapa de evaluación del proyecto. Para el 2020, se retomará la evaluación con el fin de observar si existen cambios cualitativos en los colectivos acompañados, sobre todo, y si hay una multiplicación de experiencias de economía social en la zona

El artículo se compone por dos partes: primero, la de reflexionar en torno al constructo de Economía Social y desarrollar el contexto de violencia generada por el narcotráfico en México, concretamente en el estado de Michoacán; segundo, expondremos el proyecto universitario puesto en marcha y cerraremos con los primeros resultados de este y también con los principales aprendizajes, retos y desafíos que observamos por medio de la investigación.

\section{ECONOMÍA SOCIAL Y CONSTRUCCIÓN DE PAZ}

En primer lugar, es preciso señalar que entendemos la Economía Social como un proyecto económico y político que ensaya nuevas formas de organizar, gestionar, producir, comercializar y consumir, a partir de la apropiación de valores que permitan 
construir relaciones sociales basadas en la cooperación, la equidad, la justicia y la solidaridad. Por tanto, la Economía Social pone en el centro a las personas a través del trabajo asalariado libre de explotación, del reconocimiento de la fuerza de trabajo y la propiedad colectiva de los medios de producción, en donde se recupere y potencie la dignidad de las personas en favor del desarrollo integral de ellas y de los territorios o grupos sociales de los que forman parte.

En este sentido, pensamos que al replicar las experiencias de Economía Social en zonas históricamente empobrecidas y ahora violentadas por el narcotráfico, se desarrollarán herramientas solidarias que contribuirán a construir sociedades menos violentas al generar opciones económicas sostenibles con bienestar colectivo.

Por tal motivo, las preguntas que guiaron esta investigación son: ¿en qué medida los movimientos de Economía Social contribuyen a fomentar relaciones sociales no violentas en territorios donde permea la violencia criminal?, ¿qué desafíos presentan estas iniciativas?, ¿cómo saber que la Economía Social está contribuyendo a la gestión de los conflictos de manera no violenta?, ¿qué tipo de indicadores o procesos tendrán que gestarse para saber el impacto de la Economía Social en la pacificación de las zonas de conflicto generado por el narcotráfico?

Lo anterior permite entender que la Economía Social es una respuesta a las desigualdades e inequidades históricas producto de la acumulación del capital y agravadas por la etapa neoliberal, que privilegia la generación de capital a través del despojo y la libre circulación del capital financiero en detrimento del capital productivo; esto fomenta el desempleo, más pobreza y, en consecuencia, amplía la brecha de desigualdad y genera procesos de expulsión?. Por tal motivo, la Economía Social pone al trabajo como el elemento principal para generar valor en beneficio de las personas que participan en estas cadenas productivas; privilegia la propiedad colectiva de los medios de producción y, con ello, el valor de uso sobre el valor de cambio, y reparte los beneficios de manera equitativa entre sus miembros y en beneficio de los territorios donde se insertan estos ejercicios.

En este sentido, la Economía Social se inserta en la necesidad de buscar alternativas de vida digna para todos aquellos excluidos de la forma de desarrollo concebida por el capital y también para generar relaciones sociales más incluyentes en todos los integrantes de una sociedad, sin distinción de clase. Es decir, la Economía Social cuestiona y da horizontes de vida digna a las poblaciones desgarradas por la

1 Saskia Sassen. EXPULSIONES: BRUTALIDAD Y COMPLEJIDAD EN LA ECONOMíA GLOBAL. Buenos Aires: Editorial Katz. (2015). 
viabilidad de "desarrollo" de una minoría a costa de la inviabilidad ecológica y política para la mayoría de la población que aspira a ello².

Las experiencias de Economía Social se organizan para satisfacer las necesidades económicas y sociales de sus asociados y de los territorios en donde se insertan, a través de posibilitar trabajo y producción o prestar servicios a sus asociados y a sus territorios. En esta economía, se opera con valores de uso: el superávit puede o no existir, se busca que sí exista para construir circuitos de sostenibles, pero este beneficio económico es colectivo ${ }^{3}$.

Sin embargo, entre los estudiosos de la Economía Social José Luis Coraggio señala que en los ejercicios de Economía Social hay zonas grises cuando aplicamos estas definiciones por enumeración de situaciones reales, y ante ello señala los siguientes ejemplos: cooperativas que han perdido el ideario de la cooperación y funcionan como empresas de capital tanto hacia afuera como hacia adentro; cooperativas de trabajo que son apéndices de empresas de capital, instrumentalizadas para ocultar formas de sobreexplotación del trabajo ajeno y evadir el principio de redistribución fiscal; fundaciones de gestión verticalista que dan cobertura cosmética a las empresas de capital, etc. ${ }^{4}$.

De acuerdo con lo anterior, es preciso acentuar que las organizaciones de Economía Social no pueden existir fuera de sus relaciones con otras organizaciones de la misma Economía Social, de las empresas de capital, de las organizaciones estatales y sobre todo existen dentro de un sistema con dominio de capital, que tiende a introyectar en las organizaciones una ética de mercado capitalista y genera un campo de fuerzas, como diría Bourdieu, que no puede verse como un "afuera" sino que las atraviesa y constituye como formas concretas.

Por tanto, entendemos la Economía Social no tanto como una realidad existente que se reproduce sobre sus propias bases, sino como una propuesta transicional de prácticas económicas de acción transformadora, conscientes de la sociedad que quieren generar desde el interior de la economía mixta actualmente existente y que van en dirección a otra economía, otro sistema socioeconómico, organizado por el principio de la reproducción ampliada de la vida de todos los ciudadanos-trabajadores, en contraposición al principio de la acumulación de capital. Por ello, Coraggio lo

2 María Eugenia Sánchez Díaz de Rivera. El despojo, el racismo y los desgarramientos civilizatorios. EUREKA 12. 2018. Pág. 27-47.

3 Mario César Elgue. LA ECONOMÍA SOCIAL DEL SIGLO XXI. IDEAS Y EXPERIENCIAS ARGENTINAS Y LATINOAMERICANAS. Buenos Aires: Editorial Corregidor. (2014)

4 José Luis Coraggio. ECONOMÍA SOCIAL, ACCIÓN PÚBLICA Y POLítICA. Buenos Aires: Ediciones ciccus. (2008). Pág. 34. 
denomina Economía del Trabajo para contraponerlo a la Economía del Capital, algo que el término "Economía Social no logra"5.

Como lo señalamos en párrafos anteriores, podemos observar que las experiencias de Economía Social se encuentran ensayando formas distintas de hacer economía con distintos claroscuros, avances y retrocesos. Sin embargo, podemos resaltar los logros que las diversas experiencias han tenido al poner la toma de decisiones democráticas y el bienestar colectivo en el centro el trabajo. Es decir, los ejercicios de Economía Social cumplen un rol democratizador: generar y potenciar los circuitos que conecten la producción con la comercialización, eliminando intermediaciones parasitarias que impiden el desarrollo sustentable del sector. También, han generado trabajo con una retribución más equitativa y justa en cuanto al trabajo realizado, y en acuerdo con el resto de la organización de Economía Social.

El hecho de que la Economía Social constituya un subsistema y no un sistema no significa minimizar su ethos asociativo ni sus potencialidades, como tampoco desconocer su identidad cultural y su importante rol en la cohesión social no solo comunitaria y en la satisfacción más justa de las necesidades. No obstante, ello implica que no hay que idealizarla, adjudicándole objetivos maximalistas, evitando así decepciones posteriores paralizantes, sino que se trata de comprender que no está en condiciones de transformar unilateralmente la sociedad ${ }^{6}$.

Por otra parte, al inicio de este trabajo hemos señalado que la hipótesis que guio la puesta en marcha del proyecto, y en consecuencia la investigación, es que la Economía Social puede contribuir a construir relaciones sociales no violentas en sociedades violentadas, en este caso por el crimen organizado. En tal sentido, la paz implica la promoción de una cultura democrática que permita dirimir los conflictos de manera plural, pacífica e incluyente. Que esa construcción de paz atienda de fondo las causas que originaron la violencia derivada de la histórica exclusión económica y social de poblaciones que han permanecido al margen de los beneficios del desarrollo del capital.

De acuerdo con la experiencia de violencia derivada del narcotráfico en Colombia, consideramos que la puesta en marcha de experiencias de Economía Social en México en territorios violentados sobre todo por el narcotráfico puede darnos más elementos a analizar, aprender, dialogar y retroalimentar en ambos países, en una lógica de cooperación también académica que nos permita entender las condiciones que fomentan la reproducción de estas formas sociales que rompen con el tejido

5 Id., pág. 37.

6 Mario César Elgue, supra, nota 4, pág. 32. 
social y, también, las opciones de construcción de relaciones sociales no violentas en territorios azotados por el crimen organizado.

En este sentido, la experiencia colombiana plasmada en el libro Economía Social en contextos de violencia: México y Colombia señala que la justicia transicional consiste en generar transformaciones radicales del orden jurídico, político y social. Se utiliza la paz territorial como la estrategia que permitirá la reunificación nacional y la materialización de los derechos humanos, lo cual contribuye a la reparación integral de las víctimas y a la reconciliación nacional?

La idea de la reparación transformadora surge del concepto de enfoque transformador de los conflictos que se desarrolló finales de la década de los setenta, cuando se constató que los conflictos se deben a fricciones en la estructura social, ya sean conflictos armados, políticos o sociales. Por esa razón, para solucionarlos los integrantes de la sociedad deben trascender tales contradicciones y permitir la transformación de las condiciones asimétricas mediante acuerdos y acciones que lleven a la construcción de relaciones sociales más armónicas y, sobre todo, reparadoras que atiendan las desigualdades estructurales. Desde esta perspectiva, los conflictos se ven como potencial para el cambio, para construir dinámicas inclusivas y reparadoras.

De acuerdo con diversos autores, las causas estructurales de los conflictos tienen dos dimensiones: la dimensión sustantiva, que se refiere a la situación política, económica y social que gobierna a la sociedad; y la dimensión relacional, que comprende los estereotipos, los prejuicios y las percepciones reinantes en la sociedad. Cuando estas causas persisten y la reparación se centra en el daño sufrido en menoscabo del perjuicio generado "por el hecho victimizante y se procura restituir a la persona al estado anterior a la violación, se mantendría a la víctima en un continuo espacio de carencia y necesidad, de desigualdad y discriminación que generaría repetidas victimizaciones, aunque el conflicto armado haya desaparecido"8.

En vista de lo anterior, el establecimiento de una paz duradera y de reconciliación requiere una especial consideración a los derechos económicos, sociales y culturales como base para transformar la calidad y el acceso a los recursos y servicios sociales necesarios para mantener una vida digna. Como parte de esa consideración a los derechos económicos, la construcción de paz necesita, como principal motor, una economía incluyente que ponga en el centro el beneficio de las personas a través

\footnotetext{
7 Tania Bolaños e Israel Biel. Reparaciones transformadoras para una paz con justicia social en Colombia. Coord. Nadia Eslinda Castillo Romero. ECONOMíA SOCIAL EN CONTEXTos DE VIOLENCIA: MÉXICO Y ColomBIA. Puebla: Universidad Iberoamericana Puebla; Universidad Cooperativa de Colombia. (2018). Pág. 54.

Id., pág. 58.
} 
de la dignificación de su trabajo y en beneficio de los grupos sociales y los territorios, a fin de que dinamicen procesos de largo aliento en una economía que los beneficie a todos. Además, necesitamos emprender una pedagogía para la paz que contribuya a desarmar el pensamiento, la palabra y desde luego la acción. Un movimiento cultural y social que se preocupe por la equidad social, la igualdad de derechos, la democracia, la sustentabilidad ambiental y la paz.

Por tal motivo, en el caso colombiano la idea de una paz duradera no es nueva. Desde tiempo atrás, las comunidades rurales, a lo largo de los conflictos armados derivados del crimen organizado, han construido diversas iniciativas de paz desde lo local. Podemos referirnos a las zonas de Reserva Campesina, las Juntas de Acción Comunal Rural, las Comunidades de Paz, los refugios y campamentos humanitarios, y los programas de desarrollo y paz diseñados como forma de enfrentar el abandono estatal 9 .

Aunado a lo anterior, construir la paz supone crear y facilitar territorios donde esta sea posible, espacios donde se procuren prácticas concretas transformadoras. Para ello, es importante enriquecer las perspectivas de la paz que transciendan los acuerdos entre actores armados que se enfrentan por ganar la hegemonía en un territorio, pero sin que haya transformaciones profundas en la sociedad. Como lo hemos señalado, no se puede construir la paz sin que se atiendan y combatan las causas estructurales que originaron esa violencia.

En consecuencia, entendemos el territorio como el espacio en donde la vida cotidiana sucede, es un espacio de producción y reproducción social, resultado de la dinámica de las fuerzas del mercado. También, es parte integrante de un complejo proceso de signos que proporciona orientación y significado a la vida cotidiana de una población ${ }^{10}$.

Observamos que en el caso de Colombia, a partir de los Acuerdos de Paz signados entre el Estado colombiano y las extintas Fuerzas Armadas Revolucionarias de Colombia (Farc) en 2016, se concreta desde el Gobierno el fomento de la construcción de los territorios de paz, en los que se establezcan contextos y escenarios donde la sociedad conviva en la búsqueda de la democracia, la participación, la equidad, la justicia y un progreso social incluyente. Lo anterior permitirá asociar la paz a procesos de paz mucho más amplios, profundos e incluyentes ${ }^{11}$.

\section{Id., pág. 64.}

10 David Harvey. EL NUEVo IMPERIALISmo. Madrid: Ediciones Akal. (2004).

11 Sohely Rúa y Verel Elvira Monroy. Territorio solidario para la paz, un modelo de integración económica en Colombia. Coord. Nadia Eslinda Castillo Romero. ECONOMÍA SOCIAL EN CONTEXTOS DE VIOLENCIA: MÉXICO Y COLOMBIA. Puebla: Universidad Iberoamericana Puebla; Universidad Cooperativa de Colombia. (2018). Pág. 80. 
En este sentido, el modelo de Territorios Solidarios para la Paz, formulado teórica y empíricamente por la Universidad Cooperativa de Colombia, plantea la pertinencia social y económica no solo de las prácticas de la Economía Social en general, sino también de un modelo de integración de tipo solidario en un contexto específico de posconflicto con una expectativa de poder replicarse. Los Territorios Solidarios son una apuesta de innovación social que busca generar transformaciones económicas y sociales desde y con la comunidad siendo actores protagónicos de su propio desarrollo fundamentado en la solidaridad social'².

Los Territorios Solidarios se refieren a la integración solidaria, cuyo eje central es la creación o el fortalecimiento de mercados locales y regionales solidarios articulando tres dimensiones: económica, sociocultural y política. Es decir, la creación de un mercado local significa identificar qué se produce en el territorio, dónde se comercializa, con qué calidad y características, y del lado del consumo lleva la pregunta por la intermediación existente en los mercados convencionales. También, es la construcción de una cultura para la solidaridad que integra un "nosotros" para sustentar lógicas locales vinculadas a otras prácticas globales. La tercera dimensión de este constructo nos implica un marco político para la continuidad a los procesos sociales, así como la alineación del plan de desarrollo y la política pública que fomente la construcción de economías sociales en la construcción de paz ${ }^{13}$.

En el caso de México, la apuesta de la Universidad Iberoamericana Puebla es impulsar la formación, capacitación y profesionalización de las empresas de Economía Social y, por tanto, reforzar la integración y el fomento de Circuitos de Economía Social (CES) como mecanismos que construyan otro modelo económico en favor de generar sociedades armónicas, dinamizando con ello procesos económicos locales. En este sentido, los CES se definen como el conjunto de mecanismos económicos, sociales y productivos implementados en un territorio determinado, con el objetivo de atraer, producir y mantener la riqueza entre sus habitantes, a fin de generar trabajo decente, ingresos dignos, la repartición de la riqueza y el incremento en el bienestar, inspirando así conductas sociales democráticas. En pocas palabras, "hacer que lo nuestro sea nuestro".

Los CES pueden incluir uno o más procesos colectivos de producción, comercialización, consumo, financiamiento, desarrollo tecnológico y humano, que promuevan el desarrollo económicamente viable, ambientalmente sostenible y socialmente

12 Id., pág. 82.

13 Sohely Rúa Castañeda, et al. La integración económica desde la perspectiva solidaria. Sohely Rúa Castañeda, et al. MODELOS DE INTEGRACIÓN ECONÓMICA SOLIDARIA: TEORÍA Y Acción. Bogotá: Ediciones ucc. (2018). Pags. 27-29. 
justo. Para lograr su propósito, la implementación de proyectos en el marco de los CES deberá basarse en los principios y los valores de la Economía Social: la autogestión y la participación democrática, la solidaridad, la corresponsabilidad y el apoyo mutuo, la equidad, la libre adhesión, la educación y formación cooperativa constante, la rendición de cuentas y la transparencia, la inter-cooperación, los vínculos con otras organizaciones de la Economía Social y la adopción de innovación ${ }^{14}$.

De acuerdo con lo anterior, observamos que los Territorios Solidarios y los CES son mecanismos que permiten dinamizar las economías locales para generar un mercado local que beneficie a las empresas gestionadas bajo los principios de Economía Social; la idea es que el impulso de estos mecanismos apoye la construcción de otro modelo social y económico que contribuya a la construcción de relaciones sociales no violentas en territorios violentados, sobre todo por el crimen organizado, tal es el caso de México y Colombia.

Por ello, consideramos que la Economía Social, al favorecer valores de solidaridad, convivencia y respeto por el otro, poniendo en el centro el trabajo y no el capital, puede ayudar en la construcción diaria y dinámica de relaciones sociales pacíficas.

\section{EL CONTEXTO DE VIOLENCIA EN CHERÁN Y TANCÍTARO EN MICHOACÁN, MÉXICO}

En México, la política de combate al narcotráfico del gobierno de Felipe Calderón (2006-2012), continuada por el de Enrique Peña Nieto (2012-2018), fracturó en formas aún poco dimensionadas los niveles de convivencia, sumiendo en un trauma social al país a partir de las muertes masivas consecuencia de dicha política. La nueva sensibilidad generada ante esta violencia, caracterizada por su banalidad, será de larga reversión ${ }^{15}$

Hasta antes del 2006, en México la industria del tráfico de drogas mantenía un ejercicio de bajo perfil, sin incidir de manera violenta en la dinámica social cotidiana y sin disputa por mercados. Esta práctica fue lo que se transformó. A partir de la "guerra contra el narcotráfico" iniciada por el gobierno de Felipe Calderón, esta industria se modificó tanto en su expansión territorial como en la diversificación de actividades más allá de la siembra y el trasiego de sustancias ilegales; así mismo,

14

15 Antonio Fuentes-Díaz. Narcotráfico y defensa comunitaria en "Tierra Caliente", Michoacán, México. CIENCIA UAT 10. 2015. Pág. 68-82. 
esta diversificación ha sido voraz, lo que explicaría la atrocidad de la disputa por los mercados y sus territorios ${ }^{16}$.

En este contexto, a inicios de la década de los dos mil, en el estado mexicano de Michoacán se comenzó a ver una nueva forma de operación, con la aparición de decapitaciones, colgamientos, narcomantas y una serie de formas espectaculares de violencia que están en deuda con las técnicas de contrainsurgencia implementadas a nivel de confrontación militar por el brazo armado del Cartel del Golfo: Los Zetas, quienes introdujeron ese repertorio en el enfrentamiento por la hegemonía territorial con otras organizaciones criminales, en el trasiego, venta de sustancias ilegales y cobros de piso ${ }^{17}$.

Ante la instauración de este orden criminal, se fracturó la antigua relación de reciprocidad entre las actividades ilegales del narco y las comunidades. Con esta tesis, se permite entender el fenómeno de violencia reactiva que tuvo lugar en Michoacán a principios del 2013, como la fractura de formas legítimas del ilegalismo que hizo posible el surgimiento del movimiento armado de los grupos de defensa comunitaria, quienes se opusieron al orden criminal predatorio impuesto por el cartel hegemónico en su colusión con el poder político local: Los Caballeros Templarios ${ }^{18}$.

En el caso de Cherán, municipio del estado de Michoacán, el 15 de abril de 2011 pobladores se organizaron para la defensa de su territorio frente a la tala clandestina del bosque por parte del grupo criminal Los Caballeros Templarios. La conformación del grupo de defensa del bosque escaló en el contexto de las elecciones estatales del 2011 hacia el establecimiento de un Concejo Mayor sustentado en usos y costumbres ${ }^{19}$. Así mismo, funciones estatales de seguridad y vigilancia instaurarían desde entonces un gobierno autónomo desligado de los partidos políticos, es decir, a partir de esta toma del poder, los partidos políticos fueron expulsados del municipio de Cherán ${ }^{20}$.

Así como sucedió en prácticamente todo el territorio del estado de Michoacán, desde el 2006 con la presencia del grupo criminal La Familia Michoacana y a partir del 2009 y hasta el 2013 con el grupo criminal Los Caballeros Templarios, el municipio de Tancítaro padeció el dominio de estas dos agrupaciones por medio del ejercicio de la violencia. El modo de operar era muy similar a lo practicado en otros municipios: extorsión, secuestro, desapariciones, asesinatos, etc. El interés principal de ambos

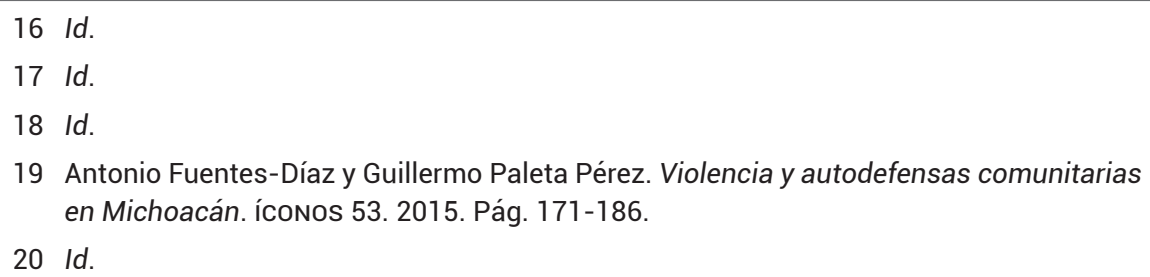


grupos estaba en el hecho de que se podían obtener recursos abundantes (cobro de cuotas, despojo de bienes, etc.), ya que la producción de aguacate en el territorio empezó a crecer de forma importante, constante y progresiva a partir del año $2003^{21}$.

Tancítaro es otro de los 113 municipios el estado de Michoacán de Ocampo; su principal actividad económica es el cultivo del aguacate, seguida por la agricultura de temporal (maíz, café, camote, jitomate, frijol) y por el aprovechamiento forestal. Cabe señalar que México es el principal productor de aguacate a nivel mundial (1,7 millones de toneladas de producción anual). El municipio de Tancítaro, conocido como "la capital del aguacate", es el aportador número uno a esta cifra con 200000 toneladas de producción anual, es decir, el 11,7\% de producción nacional; sin embargo, este municipio mantiene índices de pobreza y desigualdad apremiantes ${ }^{22}$.

En Tancítaro, el cobro de cuotas y extorsiones de Los Caballeros Templarios por el supuesto servicio de protección territorial y de seguridad fue en aumento a tal grado que, en el 2013, llegaron a cometer actos atroces como destrozos, violaciones de mujeres, desapariciones y asesinatos a quienes se negaban a pagar las cuotas o a quienes no completaban el monto solicitado cada periodo. Las cuotas establecidas para entonces eran de 200 pesos mexicanos (10 dólares) mensuales a trabajadores del campo y 2000 pesos (100 dólares) anuales por hectárea a productores de aguacate. En dos ocasiones, los criminales incendiaron empacadoras de aguacate, afectando seriamente a los dueños de esos negocios. Se supo, incluso, de casos en los que familias enteras eran asesinadas para despojarlos de sus propiedades ${ }^{23}$.

Fue hasta el 16 de noviembre de 2013 que, como resultado de una solicitud cautelosa a los grupos de Autodefensas, estos ingresaron por uno de los accesos principales de la zona suroccidente del territorio de Tancítaro. Una de las primeras acciones emprendidas por los grupos de Autodefensas fue la de desarmar y quitar las patrullas a los policías municipales coludidos con el crimen organizado. La "limpia" comenzó por las comunidades de la zona nororiente del territorio, advirtiendo a los "templarios" que era mejor que ellos se entregaran, antes de que los Autodefensas fueran personalmente por ellos ${ }^{24}$.

21 Nelson M. García González. Desafíos del desarrollo comunitario y Economía Social en territorios criminalizados. Coord. Nadia Eslinda Castillo Romero. ECONOMÍA SOCIAL EN CONTEXTOS DE VIOLENCIA: MÉXICO Y COLOMBIA. Puebla: Universidad Iberoamericana Puebla; Universidad Cooperativa de Colombia. (2018).

22 Id.

23 Id.

24 Id. 
Esta intervención, según testimonios, devolvió la tranquilidad a la población en muy poco tiempo, aunque sin dejar de lado el temor que se experimentó durante los enfrentamientos entre criminales y Autodefensas.

\section{EL PROYECTO: "FORTALECIMIENTO DE PROYECTOS ECONÓMICOS EN TERRITORIOS DE ALTA VULNERABILIDAD Y SITUACIONES DE VIOLENCIA"}

Como lo mencionamos en párrafos anteriores, el proyecto "Fortalecimiento de proyectos económicos en territorios de alta vulnerabilidad y situaciones de violencia" lo implementó el LAINES de la Universidad Iberoamericana Puebla. El objetivo del proyecto fue la formación de orientadores de Economía Social que apoyaran la generación y el acompañamiento de empresas en zonas históricamente empobrecidas y ahora violentadas por el narcotráfico para que, por medio del trabajo comunitario, emprendieran herramientas solidarias que contribuyeran a la pacificación social.

Este proyecto se llevó a cabo en municipios de los estados de Michoacán, Guerrero y Oaxaca. Para esta investigación, se tomó como referencia a los municipios de Cherán y Tancítaro, de Michoacán, por la presencia allí de uno de los actores aliados para llevar a cabo este proyecto: el Centro de Investigación y Acción Social por la Paz de la Compañía de Jesús en México y con ello, contar con mayores facilidades para acceder a estos territorios.

Por tanto, durante el 2016, que fue el año de la puesta en marcha del proyecto de formación de orientadores, se tuvieron los siguientes resultados en Tancítaro y Cherán: doce empresas acompañadas, diez orientadores formados y dos dinamizadores formados.

Cabe señalar que la figura del orientador se refiere a aquella persona que acompaña a cada emprendimiento en su consolidación empresarial desde la lógica de la Economía Social. Por su parte, la figura del dinamizador se refiere a la persona que tiene un conocimiento mayor del territorio en donde se implementan las iniciativas empresariales y que conoce a diversos actores del lugar, con los cuales se pueden generar alianzas y redes para ir construyendo los CES. 


\section{Metodología}

Para llevar a cabo la investigación de resultados del proyecto "Fortalecimiento de proyectos económicos en territorios de alta vulnerabilidad y situaciones de violencia", planteamos el proceso en dos niveles:

1. Sondeo de lo que existe: cuántas empresas existentes fueron acompañadas por los orientadores formados. Evaluar los resultados obtenidos del acompañamiento y de la gestión de la empresa de Economía Social.

2. A partir de estos resultados, analizar el efecto de los ejercicios de Economía Social en contextos violentados por el narcotráfico tanto en los integrantes de estos, como en los espacios de socialización (familia, amigos, escuela, vecinos, comunidad).

Tomando como referencia estas inquietudes, se generó un Plan de Evaluación a partir de los objetivos del proyecto y de algunos indicadores del Balance Social Cooperativo que nos orientaran en la observación de los principios y valores de la Economía Social en las organizaciones que el proyecto universitario acompañó en los municipios de Cherán y Tancítaro.

Para cumplir con el primer nivel de la investigación (revisar los resultados de permanencia del proyecto implementado en el 2016 y el 2017), generamos indicadores que nos permitieran evaluar los resultados de la gestión de una empresa desde la Economía Social, a saber:

a) Indicadores económicos: empleos generados, formalidad económica, ingreso económico, actividad económica, dependientes económicos.

b) Indicadores sociales: equidad de género, toma de decisiones, nivel de escolaridad, seguridad social, relación con la comunidad/territorio, relaciones entre cooperativas.

c) Indicadores técnico-productivos: productividad en el trabajo, producción bruta, consumo intermedio (costos variables de materias primas e insumos), nivel de ventas, valor agregado (producción bruta-consumo intermedio).

Aunado a lo anterior, para indagar sobre la apropiación de principios, valores y prácticas de Economía Social, generamos preguntas que nos permitieran observar la construcción de otra economía más allá de la gestión empresarial. Las preguntas que guiaron este propósito fueron: 
- ¿Existen otros beneficios que se generan en la empresa de Economía Social además del económico?

- ¿Hay actividades fuera de la empresa que realicen sus integrantes?

- ¿Cómo contribuyen los principios y valores de la Economía Social en la resolución de conflictos en la vida cotidiana?

- ¿Cómo contribuyen los valores de la Economía Social en la construcción de un tejido social armónico y solidario en zonas violentadas por el narcotráfico?

En esta primera etapa de la investigación, se aplicaron diez encuestas al mismo número de empresas que se identificaron como beneficiarias de este proyecto. También, se trabajó en dos árboles de sueños, los cuales se construyeron en empresas de Cherán y Tancítaro, a saber: la empresa La Esperanza de Pareo, en Tancítaro, se dedica a la producción, procesamiento y comercialización del café; y las empresas de textiles Textiles Mary y Textiles Lety, en Cherán. La selección de las empresas que trabajaron árboles de sueños fue intencionada de acuerdo con la disposición que tuvieron de trabajar en este ejercicio.

En la encuesta, se observaron dos dimensiones. La dimensión socioeconómica incluye medición de ingresos, acceso a la alimentación, vivienda y educación. En la dimensión empresarial, se priorizó evaluar los procesos de administración, capacidad productiva, toma de decisiones, participación en redes, alianzas con otras empresas, participación en actividades de la comunidad, y por último, la aplicación de los principios del cooperativismo que implementa la empresa de Economía Social.

De acuerdo con los valores y principios de la Economía Social, la empresa se observa democrática en cuanto a la toma de decisiones, ya que se hace en Asambleas con el total de socios de las empresas, por ello, se sienten incluidos en los acuerdos generados. Por otro lado, participan con otras empresas de Economía Social para ejercicios de comercialización, y apoyan a la comunidad a través de generación de empleos en las actividades políticas y festivas.

Al observar los resultados del árbol de sueños, entre sus principales miedos está que la empresa no cumpla sus expectativas en ventas y genere endeudamiento. Entre los compromisos que ellos tienen se encuentra mejorar las condiciones de trabajo, sobre todo que se refleje en un salario mayor. Entre sus sueños está tener mayores estándares de calidad y diversificar sus mercados.

En cuanto a los resultados de la encuesta de dos empresas del rubro textil: Textiles Mary y Textiles Lety, en Cherán, específicamente de bordado y confección, a diferencia de la anterior, nos encontramos que son empresas jóvenes que tienen 
alrededor de tres a cuatro meses de formación, lo que representa un reto para su consolidación y profesionalización; sin embargo, podemos observar que los acompañamientos empresariales rindieron fruto. Son empresas compuestas en su totalidad por diecisiete mujeres, generando una forma de autoempleo, aunque en su mayoría tienen otra fuente de ingresos, ya sea por sus esposos o por otros trabajos.

En cuanto a los valores y los principios de la Economía Social, la toma de decisiones es democrática, participativa e incluyente, debido a que en las narrativas señalan que acostumbran a tener la Asamblea como el órgano máximo de decisión en donde tienen cabida todos los socios; y como los señalan los principios y valores de la Economía Social, está inspirada en los principios cooperativos. Se busca que el consenso prevalezca en los asuntos que se discuten en las Asambleas como medio para la toma de las decisiones y no la mayoría. En cuanto a la participación en redes, estas se organizan para comercializar sus productos. En este sentido, en cuanto a la participación democrática de los socios y la participación de las mujeres en cargos representativos de las empresas, observamos lo siguiente:

Fuente : Elaboración propia con base en los resultados de investigación.

En la gráfica, observamos que la participación de las mujeres en cargos de representación y tipo de representación aún es menor al 50 \%, siendo en Textiles Lety donde hay un porcentaje mayor de mujeres, ya sea en las comisiones de vigilancia, administrativa o bien presidiendo el grupo. Es decir que la participación de las mujeres en los cargos representativos o administrativos en el interior de las empresas de Economía Social representa un indicador de equidad a la incorporación de las actividades económicas de las mujeres, más allá de las actividades históricamente 
acuñadas, como son las tareas de cuidado. En cuanto al apoyo a la comunidad, se refleja en su participación para las actividades festivas, algunas deportivas y de apoyo económico o en especie, por parte de solo algunas de las integrantes.

En el caso de la empresa La Esperanza de Pareo, en el municipio de Tancítaro, narraron en su árbol de sueños que en junio del 2016, después de algunas charlas entre la familia Bravo, integrantes de esta empresa y colaboradores del Programa de Reconstrucción del Tejido Social, surgió La Esperanza de Pareo, una marca de café regional que está buscando desarrollarse y consolidarse como una empresa de Economía Social en Tancítaro. La familia Bravo, originaria de la comunidad de Pareo, en Tancítaro, después de conocer a los orientadores formados en el proyecto objeto de este artículo y de tener el acompañamiento en el conocimiento de los principios y valores de la Economía Social, decidieron abrirse a la posibilidad de conformar una sociedad de productores de café que lograra organizar y defender los intereses de los cafetaleros. Esta inquietud surgió a partir de la necesidad de promover el cultivo del café dentro del territorio (para abonar a la diversificación de cultivos en el ecosistema) y de mejorar las condiciones económicas de los productores, en cuanto al precio por kilo de este fruto.

Es así como, con el devenir de las reflexiones, la familia Bravo observó la posibilidad de socializar las bondades del trabajo conjunto e integrar a más productores de café a esta forma cooperativa de organización, a fin de rescatar la vocación y tradición cafetalera de esta zona del estado de Michoacán. La principal estrategia que narraron fue la de buscar clientes que creyeran en los productores, que negociaran directamente con ellos, para después abarcar cada vez más eslabones de la cadena de valor del café y ofrecer a otros productores de la región hacer sociedad cooperativa y obtener un mejor precio por kilo de café-cereza.

Una de las principales dificultades que la familia Bravo percibió en este proceso fue evidenciar los beneficios que se pueden obtener a partir de la organización, la producción y la comercialización colectiva; por ejemplo, comprar el café a productores interesados en asociarse y también organizarse para el acompañamiento colectivo de las secuelas emocionales que el crimen organizado dejó tras de sí al violentar a las personas.

Podemos argumentar que, en las organizaciones que participaron en esta primera parte de la investigación de resultados, observamos distintos cambios tanto en la organización empresarial cooperativa, como en la apropiación de los principios y valores de la Economía Social; cambios que en ocasiones son difíciles de cuantificar. Estos niveles de apropiación dependen del tiempo de formación de las organizaciones y, por ello, aún no nos queda claro si estos resultados positivos son reflejo del 
acompañamiento recibido por parte de los orientadores formados por la universidad o de la trayectoria de organización de los grupos.

Sin duda, estos primeros resultados nos arrojan información sobre las empresas que acompañaron los orientadores formados en el proyecto evaluado. Sin embargo, también nos abren una ventana de oportunidad para indagar con mayor detalle la apropiación de principios y valores de Economía Social en sus prácticas cotidianas no solo empresariales, y también si los ejercicios de Economía Social se han replicado producto de la formación de la Universidad Iberoamericana Puebla y del acompañamiento del Centro de Investigación y Acción Social por la Paz de la Compañía de Jesús en México (Jesuitas por la Paz).

\section{ALGUNAS REFLEXIONES FINALES}

Después de haber revisado los primeros resultados de la puesta en marcha del proyecto "Fortalecimiento de proyectos económicos en territorios de alta vulnerabilidad y situaciones de violencia", podemos argumentar que la forma individual, utilitarista y consumista de entender el mundo natural y la construcción de nuestras relaciones sociales es una de las principales causas de la fragmentación social. En este sentido, es preciso analizar las causas que históricamente han generado la violencia producto de la acumulación del capital y de la forma de relaciones sociales que ha favorecido. A menudo, la violencia tiene raíces económicas y, en algunos casos, otra causa de la fragmentación humana son los traumas provocados por las distintas formas de violencia que condicionan la vida en un territorio determinado. Para el desarrollo pleno de proyectos personales y comunitarios, nos lleva a pensar en tres retos principales a los que la Economía Social se puede enfrentar al momento de ponerse en marcha en territorios caracterizados por un pasado o un presente violento:

1. Romper los paradigmas actuales que legitiman la obtención de beneficios a cambio de la explotación desmedida - de la plusvalía absoluta- de las personas y el entorno natural. Por ejemplo: la acumulación como fin; la percepción mercantilizada del trabajo, las personas y las relaciones; la mercantilización absoluta de la vida; el capital como centro y referente de toda actividad económica; la idea de entender el entorno natural como recurso inagotable; el uso de fertilizantes nocivos y agroquímicos para maximizar la producción y con ello las ganancias.

2. Otro de los grandes retos que como sociedad tenemos, y sobre todo cuando acompañamos procesos de Economía Social, será visibilizar la violencia 
en todas las escalas y en todos los tipos, no solo la violencia criminal. Esto nos permitirá entender, en primer lugar, no naturalizar relaciones sociales que dirimen sus conflictos por la fuerza, sino mantener un estado de alerta y de no naturalización de la violencia en la vida cotidiana. Por lo tanto, reconocer que como sociedad nos encontramos en entornos donde hemos naturalizado la violencia nos permitirá, desde los distintos actores de la sociedad civil, diagnosticar las causas particulares que originan y acentúan la violencia en cada territorio para entonces dar respuestas acordes que contribuyan a atender las condiciones de violencia de cada territorio $y$, también, atender de manera profesional el trauma generado por esta violencia de manera individual y colectiva.

3. Desde las alianzas señaladas en el punto dos, impulsar emprendimientos de Economía Social, pero también dirigir los esfuerzos por construir CES que permitan impulsar circuitos económicos que beneficien el desarrollo territorial a través de la construcción de relaciones sociales democráticas, autogestivas y autónomas que impacten en las actividades empresariales y en todas las actividades económicas.

4. Pensar la Economía Social como proceso que contribuya a la construcción de paz, pero no como el fin último, sino como el camino hacia la construcción de una economía en favor del bienestar colectivo y que apuesta por un cambio subjetivo en la vida cotidiana. En este sentido, hemos señalado que la Economía Social cuenta con principios y valores que privilegian la libertad, el respeto del otro, la colaboración mutua, la autogestión colectiva y democrática, la igualdad de género, la equidad en la gestión de necesidades, el cuidado del entorno natural y el cuidado común para un beneficio comunitario. Por lo tanto, consideramos que la Economía Social tiene un gran potencial para construir un tejido social más armónico que con base en el respeto construya formas de vida digna para todos y, con ello, entornos pacíficos que velen por el bien común. Pero este es un proceso de largo aliento que precisa acciones cotidianas de construcción de ese horizonte.

Además de lo expuesto en párrafos anteriores, el caso de Cherán presenta otras particularidades por el proceso de autonomía política en el que derivó la expulsión de los partidos políticos y de las mafias de talamontes que devastaban los bosques de la zona. En Cherán, uno de los primeros supuestos de poner en práctica proyectos de Economía Social era aprovechar y potenciar el proceso de autonomía política que la comunidad había detonado en 2011, con el fin de impulsar ejercicios de Economía 
Social que propiciaran la construcción de un territorio con alternativas de trabajo y producción, caracterizadas por formas democráticas de gestión de los recursos, toma de decisiones y propiedad colectiva en beneficio del conjunto de la población.

No obstante, observamos que todas las iniciativas de cambio y reconfiguración social llevan un tiempo constante e inacabado, ligado a los procesos de los territorios en donde se producen estas transformaciones. Es decir, se trata de observar los procesos y no los resultados, esto es, analizar la configuración histórica de las relaciones sociales y por ende económicas que han caracterizado el escenario en donde se dan estas iniciativas de cambio. Solo comprendiendo estos tiempos es que los resultados de los acompañamientos, en este caso de Economía Social, tendrán impactos positivos en las personas, porque responderán a sus necesidades individuales y colectivas.

En este sentido, Cherán se encuentra ensayando la puesta en marcha de un proceso de autonomía política de largo aliento; no se trata solo de cambiar de instituciones de gobierno, sino también de cambiar la forma de hacer el gobierno, lo cual se aprende y se articula de acuerdo con las problemáticas y necesidades del territorio.

En vista de lo anterior, implementar ejercicios económicos alternativos de Economía Social implica no solo una nueva forma de hacer empresa o negocios, sino además organizar y entender la vida a partir de una concepción distinta, en la que se ponga en práctica diariamente y en toda la esfera de vida cotidiana el valor del trabajo asalariado y de la fuerza de trabajo en conjunto, la dignidad de las personas, la toma de decisiones democráticas, la autogestión, la participación en los asuntos públicos, la equidad entre hombres y mujeres, la autonomía; todo en pro del beneficio común de todos los que participan en los ejercicios económicos y también de los territorios en donde están insertos.

Por tal motivo, creemos que impulsar CES en zonas violentadas por el crimen organizado contribuirá a ir dinamizando y fortaleciendo las economías locales y contribuirá a la construcción de relaciones sociales más pacíficas libres de violencia. Esto también se presenta en el caso colombiano con los llamados Territorios Solidarios. Ambos procesos, tanto los CES como los Territorios Solidarios, apuestan por la creación o regeneración de una economía local que dinamice un mercado en beneficio de los territorios donde se impulsa y que genere opciones de trabajo digno y legal en espacios violentados, sobre todo, por el narcotráfico.

En este sentido, la organización de las llamadas Empresas de Propiedad Comunal, en Cherán, México, descansa sobre una estructura empresarial designada por el gobierno autónomo y propuesta y validada por la población a través de las Fogatas, que son las asambleas el órgano máximo de decisión. En estos espacios, la población que participa se reúne, discute y toma decisiones referentes a la comunidad. 
Como observamos, en el caso de las llamadas empresas comunales la población delega en una estructura organizativa la administración de la comunidad al gobierno autónomo, es decir, sin la participación activa de distintos actores de la población, pero los gerentes de estas empresas saben que trabajan para el beneficio colectivo además del individual.

En este sentido, podríamos argumentar que en Cherán, además de mantener las empresas comunales, se podrían dinamizar procesos de Economía Social impulsando emprendimientos colectivos de distinta índole, desde una cooperativa de producción, hasta fomentar el ahorro colectivo con la creación de una Cooperativa de Ahorro y Préstamo. Estas nuevas iniciativas de emprendimiento pueden impulsarse aprovechando a los orientadores formados en el proyecto objeto de esta investigación, quienes siendo originarios de allí tienen la ventaja de conocer la vida cotidiana de Cherán y en qué sectores económicos se podrían potenciar estos procesos.

Así mismo, impulsar los ces dinamizará los procesos económicos, y la vivencia de los principios de la Economía Social permitirá aprehender nuevos valores para organizar la vida y contribuir a la construcción de relaciones sociales en las que los conflictos se gestionen de manera no violenta. Se reconstruirá el tejido social a través de la solidaridad, la equidad, la toma de decisiones democráticas, la autonomía, el respeto, la ayuda mutua; es decir, los ejercicios de Economía Social potenciarán una economía autogestiva que permita construir relaciones económicas basadas en la cooperación, como resultado de organizar la vida cotidiana que privilegie los valores señalados en favor de la vida.

Finalmente, observamos que la autonomía económica, a través de la generación de experiencias y circuitos de Economía Social, será un proceso de largo aliento si acaso es el propósito de la comunidad de Cherán. En el 2018, no se observó un impulso fuerte y sostenido para generar estas formas autogestivas, cooperativas y democráticas de trabajo más allá de las empresas comunales. Veremos si más adelante las necesidades de la comunidad, y los avatares de la política y la economía en el municipio y en la región los Ileva a construir procesos de Economía Social, en donde se impulsen CES de manera constante y con ello se reconozca y dignifique el conjunto de la fuerza de trabajo en toda la cadena productiva y también se generen espacios de inclusión financiera, como las cooperativas de ahorro y préstamo colectivo que, a la larga, les permita ahorrar e impulsar proyectos productivos colectivos. 


\section{REFERENCIAS}

Antonio Fuentes-Díaz. Narcotráfico y defensa comunitaria en "Tierra Caliente", Michoacán, México. Ciencia uat 10. 2015. Pág. 68-82.

Antonio Fuentes-Díaz y Guillermo Paleta Pérez. Violencia y autodefensas comunitarias en Michoacán. Íconos 53. 2015. Pág. 171-186.

Antonio Fuentes-Díaz. Pluralismo violento y contextos de conflicto en América Latina. Coord. Nadia

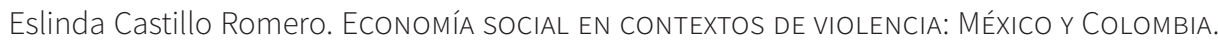
Puebla: Universidad Iberoamericana Puebla; Universidad Cooperativa de Colombia. (2018).

Carlos Askunze Elizaga. Economía solidaria. Coords. Gema Celorio y Alicia López de Munian. DiccionaRIO de EDUCACIÓn PARA EL DESARROLLO. Bilbao: Hegoa. (2007)

Claudia Luz Piedrahita, Pablo Vommaro y María Cristina Fuentes. Eds. Formación PARA LA CRíTICA Y CONSTRUCCIÓN DE TERRITORIOS DE PAZ. Bogotá: Universidad Distrital Francisco José Caldas; Clacso. (2017).

David Harvey. El NUEVo ImPERIALISMO. Madrid: Ediciones Akal. (2004).

José Luis Coraggio. ECONOmíA SOCIAL, ACCIÓN PÚBLICA Y POLíTICA. Buenos Aires: Ediciones CICCUS. (2008)

Juan Carlos Pérez de Mendiguren y Enekoitz Etxezarreta. Sobre el concepto de economía social y solidaria: aproximaciones desde Europa y América Latina. REvISTA DE ECONOmía MUNDIAL 40. 2015. Pág. 123-144.

María Eugenia Sánchez Díaz de Rivera. El despojo, el racismo y los desgarramientos civilizatorios. EUREKA 12. 2018. Pág. 27-47.

Mario César Elgue. LA ECONOMÍA SOCIAL DEL SIGLO XXI. IDEAS Y EXPERIENCIAS ARGENTINAS Y LATINOAMERICANAS. Buenos Aires: Editorial Corregidor. (2014)

Nadia Eslinda Castillo Romero. El Proyecto Mesoamérica y los movimientos de Economía Social. Coords. Roberto González Arana y Alejandro Schneider. Movimientos SOCIALES EN AmÉRICA LATINA EN EL SIGLO XX. Buenos Aires: Clacso. (2016)

Nelson M. García González. Desafíos del desarrollo comunitario y Economía Social en territorios criminalizados. Coord. Nadia Eslinda Castillo Romero. ECOnomía social EN CONTEXTOS DE 
VIOLEnCIA: MÉxico y COLOmBiA. Puebla: Universidad Iberoamericana Puebla; Universidad Cooperativa de Colombia. (2018).

Saskia Sassen. EXPULSIOnES: BRUTALIDAD y COMPLEJIDAD EN LA ECONOMíA GLOBAL. Buenos Aires: Editorial Katz. (2015).

Sohely Rúa y Verel Elvira Monroy. Territorio solidario para la paz, un modelo de integración económica en Colombia. Coord. Nadia Eslinda Castillo Romero. EConomía social EN CONTEXTOS DE VIOLENCIA: MÉxICO Y COLOMBIA. Puebla: Universidad Iberoamericana Puebla; Universidad Cooperativa de Colombia. (2018).

Sohely Rúa Castañeda, et al. La integración económica desde la perspectiva solidaria. Sohely Rúa Castañeda, et al. MOdELOS DE INTEGRACIÓN ECONÓMICA SOLIDARIA: TEORÍA Y ACCIÓN. Bogotá: Ediciones UCc. (2018).

Tania Bolaños e Israel Biel. Reparaciones transformadoras para una paz con justicia social en Colombia. Coord. Nadia Eslinda Castillo Romero. EConomía social en CONTEXTOS DE VIOLENCIA: MÉXICO y COLOMBIA. Puebla: Universidad Iberoamericana Puebla; Universidad Cooperativa de Colombia. (2018). 